\title{
Formulation and Evaluation of Mucoadhesive Buccal Tablet of Repaglinide
}

\author{
Thakare Eknath B*., Malpure Prashant S., Maru Avish D., More Yashpal M.
}

Department of Pharmaceutics, Loknete Dr. J.D. Pawar College of Pharmacy, Manur, Tal-Kalwan, Dist-Nashik (Maharashtra) 423501

\begin{abstract}
The aim of present investigation was formulation and evaluation of mucoadhesive buccal tablet of Repaglinide to study the effect of different polymers on release profile of drug for prolonged release. In this study mucoadhesive buccal tablet were prepared by direct compression method. Various rheological characteristics of the powder bed like bulk density, compressibility index, and angle of repose were evaluated and studied. Mucoadhesive buccal tablets were compressed on a 8 station mini press using 10 mm flat faced punches and were all assessed for weight variation, hardness, thickness, percent swelling index, mucoadhesive strength and in vitro release of the drug by using USP TDT 08L dissolution testing apparatus method II using a paddle at $50 \mathrm{rpm}$. Data was optimized by using $3^{2}$ full factorial design by using software named as design expert and with the help of kinetic study. The stability studies showed that there is no decrease in the drug content of all formulations for the period of 2 months.
\end{abstract}

Keywords: Buccal tablet, Repaglinide, HPMC K100M, Xanthan gum.

Article Info: Received 10 July 2019; Review Completed 17 Aug 2019; Accepted 23 Aug 2019; Available online 30 Aug 2019

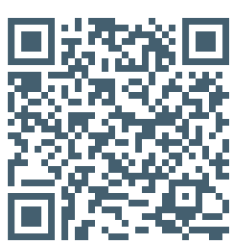

\section{Cite this article as:}

Thakare EB., Malpure PS., Maru AD., More YM, Formulation and Evaluation of Mucoadhesive Buccal Tablet of Repaglinide, Journal of Drug Delivery and Therapeutics. 2019; 9(4-A):415-424 http://dx.doi.org/10.22270/jddt.v9i4-A.3488

\section{*Address for Correspondence:}

Mr. Thakare Eknath B., Department of Pharmaceutics, Loknete Dr. J.D. Pawar College of Pharmacy, Manur, Tal-Kalwan, Dist-Nashik (Maharashtra) 423501

\section{INTRODUCTION}

Bioadhesion can be defined as a phenomenon of interfacial molecular attractive forces in the midst of the surfaces of biological substrate and the natural or synthetic polymers, which allows the polymer to adhere biological surface for an extended period of time. Among the various routes of drug delivery the oral route is perhaps the most preferred by patients and clinicians alike. However, peroral administration of drugs has disadvantages, such as hepatic first-pass metabolism and enzymatic degradation within the gastrointestinal (GI) tract, that prohibit oral administration of certain classes of drugs, especially peptides and proteins. Consequently, other absorptive mucosas are considered as potential sites for drug administration. Transmucosal routes of drug delivery (i.e., the mucosal linings of the nasal, rectal, vaginal, ocular, and oral cavities) offer distinct advantages over peroral administration for systemic effect. These advantages include possible bypass of first-pass effects and avoidance of presystemic elimination within the GI tract.

The buccal region of oral cavity is an attractive site for the delivery of drugs owing to the ease of the administration. Buccal drug delivery involves the administration of desired drug through the buccal mucosal membrane lining of the oral cavity. This route is useful for mucosal (local effect) and trans-mucosal (systemic effect) drug administration. In the first case, the aim is to achieve a site-specific release of the drug on the mucosa, where as the second case involves drug absorption through the mucosal barrier to reach the systemic circulation.

\section{Mucoadhesive drug delivery systems}

Mucoadhesive drug delivery systems are delivery systems, which utilized the property of bioadhesion of certain polymers, which become adhesive on hydration and hence can be used for targeting a drug to particular region of the body for extended period of time. The ability to maintain a delivery system at a particular location for an extended period of time has great appeal for both local as well as systemic drug bioavailability. Pharmaceutical aspects of mucoadhesion have been the subject of great interest during recent years because it provides the possibility of avoiding either destruction by gastrointestinal contents or hepatic first-pass in activation of drug.

\section{MATERIALS \&METHODS}

\section{Materials}

Repaglinide was provided as sample from Swapnroop Laboratories Aurangabad. HPMC K100M, Chitosan, dextrose, mannitol, ethyl cellulose. 
Ingredient used in formulation

Table1: Ingredient used in formulation.

\begin{tabular}{|c|c|c|c|c|c|c|c|c|c|c|}
\hline Sr. No & $\begin{array}{c}\text { Name of } \\
\text { ingredients }\end{array}$ & $\mathbf{F}_{\mathbf{1}}$ & $\mathbf{F}_{\mathbf{2}}$ & $\mathbf{F}_{\mathbf{3}}$ & $\mathbf{F}_{\mathbf{4}}$ & $\mathbf{F}_{\mathbf{5}}$ & $\mathbf{F}_{\mathbf{6}}$ & $\mathbf{F}_{\mathbf{7}}$ & $\mathbf{F}_{\mathbf{8}}$ & $\mathbf{F}_{\mathbf{9}}$ \\
\hline 1 & Repaglinide & 10 & 10 & 10 & 10 & 10 & 10 & 10 & 10 & 10 \\
\hline 2 & HPMC K 100 M & 15 & 15 & 15 & 20 & 20 & 20 & 25 & 25 & 25 \\
\hline 3 & Chitosan & 15 & 20 & 25 & 15 & 20 & 25 & 15 & 20 & 25 \\
\hline 5 & Dextrose & 35 & 35 & 35 & 35 & 35 & 35 & 35 & 35 & 35 \\
\hline 6 & Mannitol & 25 & 20 & 15 & 20 & 15 & 10 & 15 & 10 & 5 \\
\hline 7 & Ethyl cellulose & 100 & 100 & 100 & 100 & 100 & 100 & 100 & 100 & 100 \\
\hline
\end{tabular}

\section{Preformulation studies}

Preformulation studies on the obtained sample of drug for identification and compatibility studies were performed

\section{Characterization of the Drug}

\section{Organoleptic properties}

The sample of Repaglinide was studied for organoleptic properties such as colour, odour and appearance.

\section{Melting point}

The melting points of Repaglinide were determined by melting point apparatus. Observed value was compared with the reported value.

\section{Drug excipient compatibility study}

Drug excipient compatibility was performed by liquid Fourier Transform infrared. It was performed by mixing drug with excipient in equal proportion and then IR spectrum was noted for mixture using $\mathrm{NaCl}$ cell. Small amount of the mixture was placed on the sample cell, the cell was then filtered in sample holder, spectra were scanned over a frequency range $4000-400 \mathrm{~cm}-1$ with FTIR instrument and the spectral analysis were done.

Preparation of Mucoadhesive buccal tablet (By Direct compression method)

1. Weighing of ingredients

2. Milling of drug and Excipients

3. Mixing of drug and Excipients

4. Tablet compression

\section{EVALUATION OF MUCOADHESIVE BUCCAL TABLETS}

\section{Hardness test}

Hardness test was conducted for three tablets from each batch and average values were calculated.

\section{Weight variation test}

Weight variation test was performed for ten tablets from each batch using an electronic balance and average values were calculated.

Table 2: Percentage deviation in weight variation

\begin{tabular}{|c|c|}
\hline Average weight of a tablet & Percentage deviation \\
\hline $\begin{array}{c}130 \mathrm{mg} \text { or less } \\
\text { than } 324 \mathrm{mg}\end{array}$ & 10 \\
\hline 324 mg or more & 7.5 \\
\hline
\end{tabular}

Thickness

The thicknesses of buccal tablets were determined using digital micrometer (Digital Caliper, Aerospace, India). Ten individual tablets from each batch were used and the average thickness was calculated.

\section{Friability test}

Friability of twenty randomly selected tablets from each formulation were determined by using the Roche type friabilator.

\section{In vitro drug release for Repaglinide tablet}

The drug release profile was studied using USP dissolution testing apparatus method II using a paddle at 50 rpm $900 \mathrm{ml}$ dissolution fluid, $\mathrm{pH} 6.8$ phosphate buffer, was used and a temperature of $37 \pm 0.5^{\circ} \mathrm{C}$ was maintained. $5 \mathrm{ml}$ aliquots at $1 \mathrm{~h}, 2 \mathrm{~h}, 3 \mathrm{~h}, 4 \mathrm{~h}, 5 \mathrm{~h}, 6 \mathrm{~h}, 7 \mathrm{~h}, 8 \mathrm{~h}, 9 \mathrm{~h}, 10 \mathrm{~h}, 11 \mathrm{~h}, 12 \mathrm{~h}$ respectively were pipette out and the same volume was replaced with $\mathrm{pH} 6.8$ phosphate buffer. Absorbance was measured at $\lambda \max 282 \mathrm{~nm}$ and from which percentage of Repaglinide was calculated using calibration curve.

Table 3: In vitro drug release studies details

\begin{tabular}{|c|c|}
\hline Apparatus used & USP Type II dissolution test apparatus \\
\hline Dissolution medium & Phosphate buffer pH 6.8 \\
\hline Dissolution medium volume & $900 \mathrm{ml}$ \\
\hline Temperature & $37 \pm 0.5^{\circ} \mathrm{C}$ \\
\hline Speed of basket & $50 \mathrm{rpm}$ \\
\hline Sampling intervals & $1 \mathrm{Hrs}$ \\
\hline Sample withdraw & $5 \mathrm{ml}$ \\
\hline Absorbance measured & $282 \mathrm{~nm}$ \\
\hline
\end{tabular}




\section{In vitro mucoadhesive strength}

In vitro mucoadhesive strength of tablet was measured with goat Oral mucosa, using a modified physical balance. On one side of the balance, a rubber closure tied with thread was attached and on other side empty polythene bag was attached. Goat oral mucosa was obtained from a local slaughter house and stored in a phosphate buffer $\mathrm{pH}$ 6.8 upon collection. The experiments were performed within $3 \mathrm{~h}$ of collection of oral mucosa which has been separated from sheep stomach. The goat stomach mucosa was fixed to the opening of the glass vial with thread and then placed in a beaker, well packed. Phosphate buffer $\mathrm{pH} 6.8$ was added into the beaker up to the upper surface of the buccal mucosa to maintained oral mucosal viability during the experiment. The tablet was sticked to the rubber closure with cyanoacrylate glue, then the beaker was raised slowly until contact between goat oral mucosa and tablet was established. A preload of $5 \mathrm{gm}$ was placed on the clamp for 5 min (preload time) to establish adhesion bonding between tablet and goat oral mucosa. The preload time were kept constant for all the formulations. After completion of the preload time, preload was removed from the clamp and water was then added in the polythene bag by pipette in drop-wise manner, at a constant rate. The weight of water required to detach tablet from stomach mucosa was noted as in vitro mucoadhesive strength, and these experiments were repeated with fresh mucosa in an identical manner. The modified physical balance for in vitro mucoadhesive strength determination consisting of polythene bag (on one side) and rubber closure for attachment of tablet (on other side).

\section{Swelling Study}

Buccal tablet are weighed individually (W1) and placed separately in petri dishes containing phosphate buffer pH 6.8 for $8 \mathrm{hrs}$ at regular interval of time (1, 2, 4, 6 and $8 \mathrm{hr}$ ) and The tablet are removed from the petri dishes and excess surface water is removed using filter paper. The tablet are weighed (W2) and swelling index (SI) is calculated as follows

$$
\mathrm{SI}=(\mathrm{W} 2-\mathrm{W} 1) / \mathrm{W} 1
$$

\section{Drug content uniformity}

Ten tablets were accurately weighed and powder crushed in a glass pestle mortar. An accurately weighed amount equivalent to $5 \mathrm{mg}$ of pure drug was taken, and the assay was performed UV spectrophotometer.

\section{Optimization by $3^{2}$ factorial designs:}

Optimization is the key parameter in the development of any product factorial designs used to evaluate two or more factors simultaneously interactions can be determined in the factorial design. A study in which two factors and three levels are involved is called as $3^{2}$ factorial design. For the present work $3^{2}$ factorial design selected and 2 factors were evaluated at three possible levels by formulating all possible 9 formulation combination which are shown in table 3 .

Formulation code assigned to the batches

$\mathrm{X}_{1}=$ HPMC K100M

$\mathrm{X}_{2}=$ Xanthan gum

Table 4: design summary.

\begin{tabular}{|c|l|c|c|c|c|c|c|c|c|}
\hline Factor & Name & Unit & Type & Min. & Max. & $\begin{array}{c}\mathbf{- 1} \\
\text { actual }\end{array}$ & $\begin{array}{c}\mathbf{+ 1} \\
\text { actual }\end{array}$ & $\begin{array}{c}\text { Mean } \\
\text { Std. } \\
\text { Dev. }\end{array}$ \\
\hline A & HPMC K100M & $\%$ & Numeric & 15 & 25 & -1.00 & 1.00 & 40 & 12.18 \\
\hline B & Xanthan Gum & $\%$ & Numeric & 15 & 25 & -1.00 & 1.00 & 40 & 12.18 \\
\hline
\end{tabular}

HPMC K100M and Chitosan are independent variable used in the formulation. They are mucoadhesive polymer to increase the residence time of formulation in oral cavity and also show their effect on mucoadhesive strength, swelling index, in vitro drug release.

\section{Independent variable}

$\mathrm{X} 1=$ HPMC K100M

$\mathrm{X} 2=$ Xanthan gum

Dependent variable

$\mathrm{Y} 1=$ Drug release

$\mathrm{Y} 2=$ Swelling index

Y3= Mucoadhesive strength

\section{In- Vitro Drug Release Kinetic Study}

\section{Zero Order Kinetics}

A Zero order release would be predicted by the following equation,

$$
\text { Qt-Q0=K0t }
$$

Where
$\mathrm{Q} t=$ Amount of drug release dissolved in time ' $\mathrm{t}$ '

$\mathrm{Co}=$ Initial amount of drug concentration in solution.

Kot=Zero order rate constant.

When the data were plotted as cumulative \% drug release versus time, if the plot is linear then data obeys zero order kinetics with slope equal to K0. This model represents an ideal release profile in order to achieve the prolonged pharmacological action.

\section{First Order Kinetics:}

A first order release would be predicted by the following equation

$\log Q t=\log Q 0-K l t / 2.303$

Where,

$\mathrm{Q} t=$ Amount of drug released in time ' $\mathrm{t}$ '

$\mathrm{Co}=$ Initial amount of drug concentration in solution.

Klt=first order rate constant

When data were plotted as log cumulative $\%$ drug remaining versus time yields a straight line indicating that the release 
follows first order kinetics. The constant $\mathrm{K}$ can be obtained multiplying slope values.

\section{Higuchi's Model:}

Drug release from the matrix device by diffusion has been described by Higuchi's diffusion equation

\section{$\mathrm{Ft}=\mathrm{Q}=\mathrm{VD} 5 / \mathrm{T}(2 \mathrm{C}-\mathbf{5 C s}) \mathrm{Cst}$}

Where,

$\mathrm{Q}=$ Amount of drug release dissolved in time' $t$ '.

$\mathrm{Co}=$ diffusion coefficient of drug in the release matrix.

$\mathrm{Cs}=$ Solubility of drug in the matrix.

$5=$ porosity of matrix

$\mathrm{t}=$ Tortuosity

T=Time $(\mathrm{h})$

The equation may be simplified then the equation becomes,

$$
\mathrm{Ft}=\mathrm{Q}=\mathrm{KhX} \mathrm{t} 1 / 2
$$

Where,

$\mathrm{Kh}=$ Higuchi dissolution constant

When data were plotted according to this equation, i.e. cumulative drug released versus square root of time, yields a straight line, indicating that the drug was released by diffusion mechanism.

\section{PeppasKorsmeyer Equation}

In 1983 korsmeyeret. al developed a simple, semiempirical model,when diffusion is the main drug release mechanism, relating exponentially the drug release to the elapsed time (t)

\section{At $/ \mathbf{A o}=\mathrm{Kt} / \mathrm{n}$}

Where,

$\mathrm{K}=$ Constant

$\mathrm{n}=$ Release

$\mathrm{t}=$ Time

At and $A o=A b s o l u t e$ cumulative amount of drug released at times.

This is used when the release mechanism is not well known or when more than one type of a release phenomenon could be involved.

\section{RESULT AND DISCUSSION}

Preformulation study

\section{Identification and Characterization of the Drug} Organoleptic Properties

The organoleptic properties of Repaglinide such as colour, appearance, odour was observed visually

Table 5: Identification tests of Repaglinide

\begin{tabular}{|c|c|c|}
\hline Parameter & Reported value & Observed value \\
\hline Appearance & Crystalline & Crystalline \\
\hline Colour & White & White \\
\hline Odour & Odourless & Odourless \\
\hline
\end{tabular}

\section{Melting Point}

The melting point was determined by melting point apparatus and the melting point was found to be

Table 6: Melting point of Repaglinide

\begin{tabular}{|c|c|c|}
\hline Parameter & Standard & Observed \\
\hline Melting Point & $130-131^{0} \mathrm{C}$ & $128-132^{\circ} \mathrm{C}$ \\
\hline
\end{tabular}

\section{Solubility}

Solubility of Repaglinide was checked in various solvents

Table 7: Determination of drug solubility in various solvents

\begin{tabular}{|c|c|c|}
\hline Sr. No. & Solvent & Descriptive term \\
\hline 1 & Methanol & Soluble \\
\hline 2 & Water & Insoluble \\
\hline
\end{tabular}




\section{DRUG EXCIPIENTS COMPATABILITY STUDY}

\section{Infra red spectrum}

The FTIR spectrum of pure Repaglinide showed peaks in wave numbers $(\mathrm{cm}-1)$ which corresponds to the functional group present in the structure of the drug. FT-IR spectrum of Repaglinide is shown in figure 1.

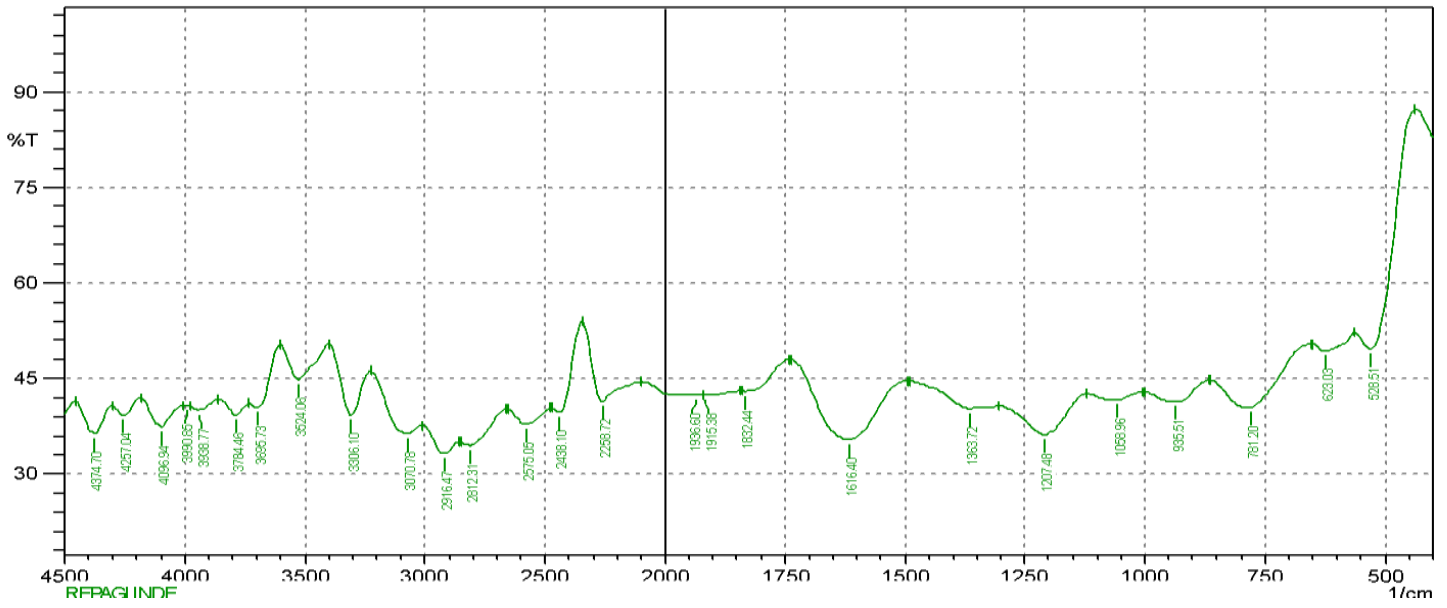

Figure 1: FT-IR Spectrum of Repaglinide.

\section{Fourier transform infra-red spectroscopy (FTIR)}

Infra-red spectra of drug and polymers showed matching peck with the drug spectra. The data obtained from the IR spectra showed no evidence of the interaction between the drug and the polymer studies. All the major characteristics pecks of the drug were present in the drug polymer combination spectra which indicate compatibility of drug with the polymers.

\section{Drug + HPMC K100M}

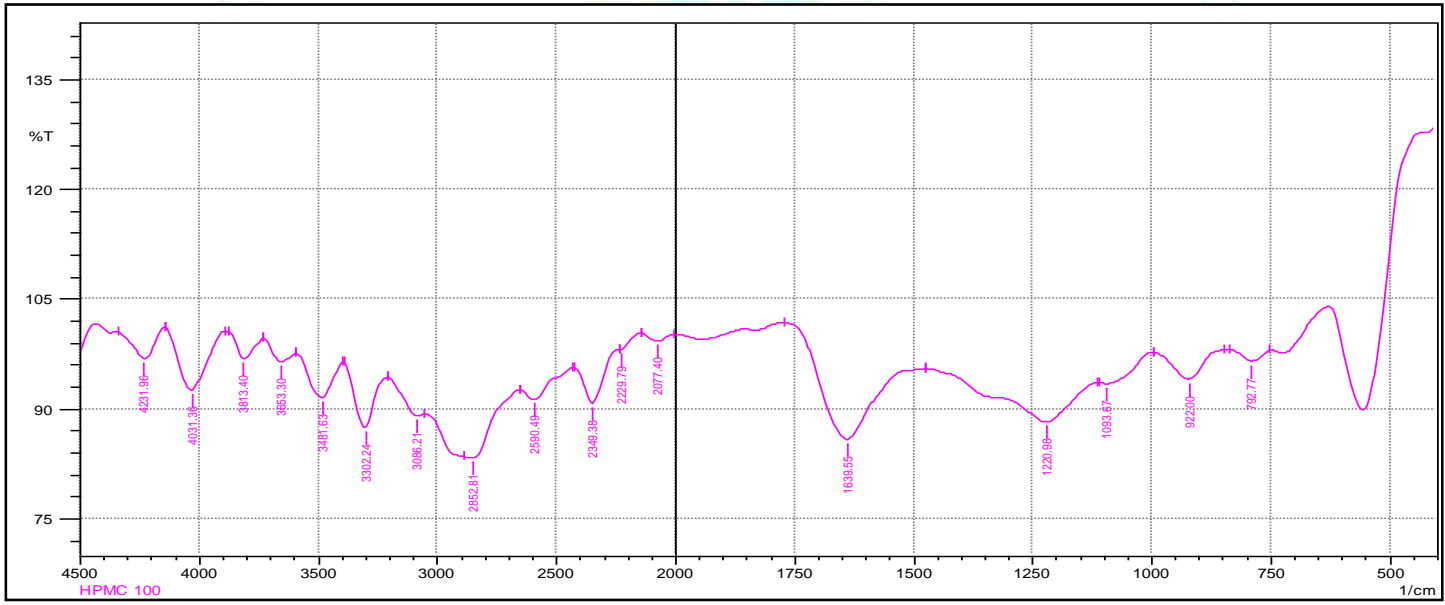

Figure 2: FTIR Spectrum of Drug + HPMC K100M

\section{Drug + Chitosan}

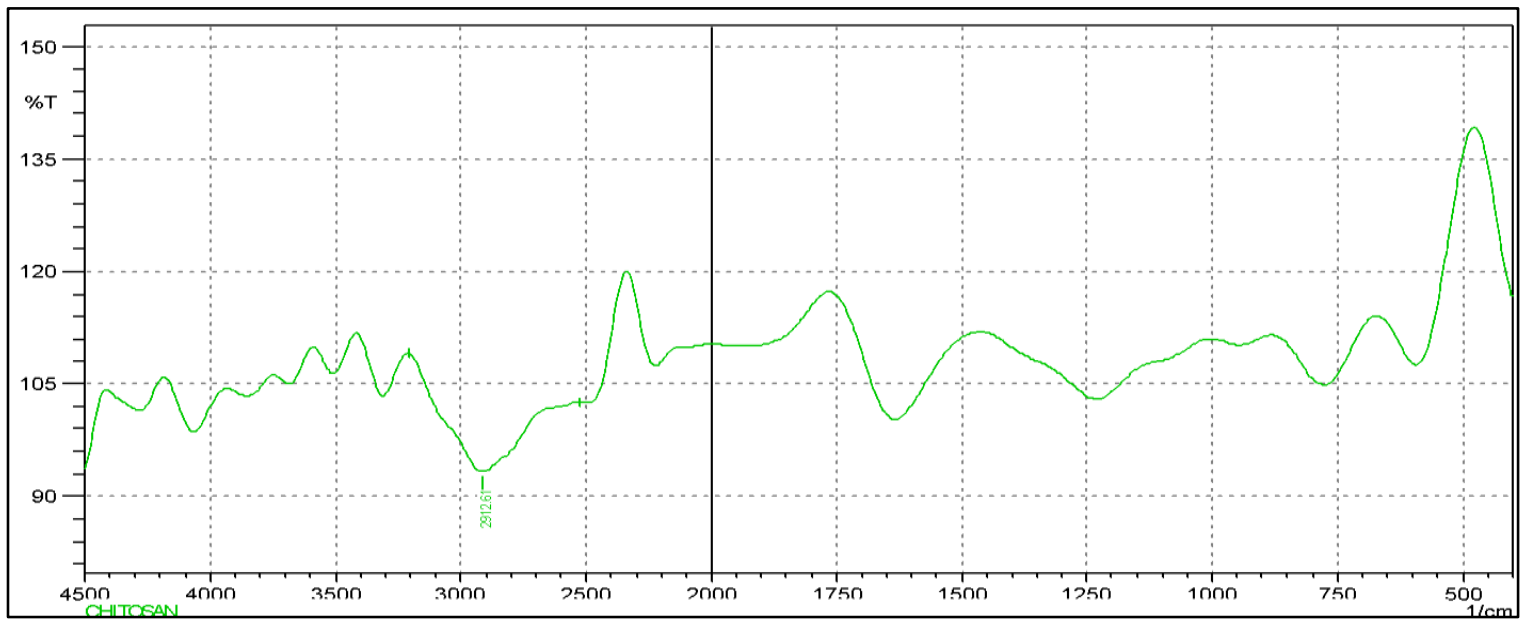

Figure 3: FTIR Spectrum of Drug + Chitosan Mixture 


\section{Differential Scanning Calorimetry}

Thermal analysis of drug was carried out using DSC. The Differential Scanning Calorimetry curve of repaglinide profiles a sharp exothermic peak at $134^{\circ} \mathrm{C}$ corresponding to its melting, and indicating its crystalline nature and purity of sample. The DSC thermogram is shown in Figure 4.

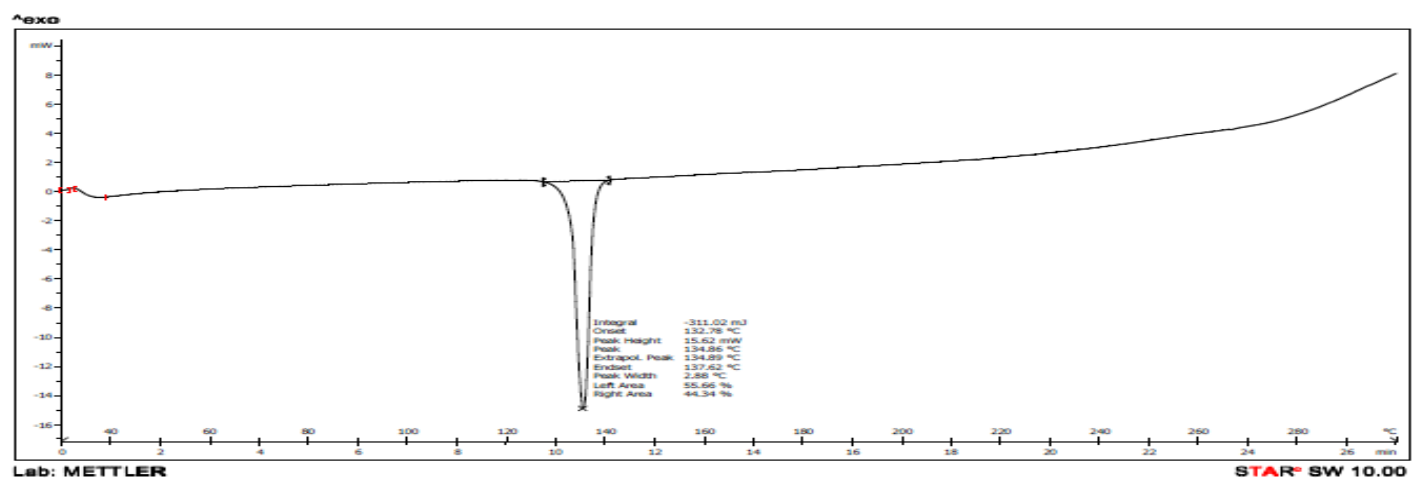

Figure 4: DSC Thermogram of Repaglinide

\section{PRE-COMPRESSION PARAMETERS}

Table 8: Pre compression parameters for Mucoadhesive buccal tablet

\begin{tabular}{|c|c|c|c|c|c|}
\hline $\begin{array}{c}\text { Formulation } \\
\text { code }\end{array}$ & $\begin{array}{c}\text { Angle of repose }\left({ }^{0}\right) \\
\text { Mean } \pm S . D^{*}\end{array}$ & $\begin{array}{c}\text { Bulk density }(\mathrm{g} / \mathrm{ml}) \\
\text { Mean } \pm \text { S.D* }\end{array}$ & $\begin{array}{c}\text { Tapped density } \\
(\mathrm{g} / \mathrm{ml}) \text { Mean } \pm \text { S.D* }\end{array}$ & $\begin{array}{c}\text { Carr's index } \\
(\%) \text { Mean } \pm S . D^{*}\end{array}$ & $\begin{array}{c}\text { Hausner's ratio } \\
\text { Mean } \pm \text { S.D* }\end{array}$ \\
\hline$F_{1}$ & $33.97 \pm 1.71$ & $0.39 \pm 0.015$ & $0.45 \pm 0.015$ & $13.33 \pm 1.45$ & $1.15 \pm 0.020$ \\
\hline$F_{2}$ & $34.59 \pm 0.79$ & $0.38 \pm 0.010$ & $0.43 \pm 0.010$ & $11.62 \pm 1.45$ & $1.10 \pm 0.013$ \\
\hline $\mathbf{F}_{3}$ & $33.40 \pm 0.86$ & $0.36 \pm 0.005$ & $0.41 \pm 0.010$ & $12.19 \pm 0.94$ & $1.13 \pm 0.011$ \\
\hline $\mathbf{F}_{4}$ & $30.46 \pm 0.83$ & $0.37 \pm 0.006$ & $0.41 \pm 0.016$ & $09.75 \pm 1.63$ & $1.10 \pm 0.008$ \\
\hline$F_{5}$ & $30.71 \pm 0.68$ & $0.37 \pm 0.011$ & $0.42 \pm 0.016$ & $11.24 \pm 1.67$ & $1.12 \pm 0.012$ \\
\hline$F_{6}$ & $32.82 \pm 1.05$ & $0.38 \pm 0.008$ & $0.42 \pm 0.008$ & $09.52 \pm 1.28$ & $1.10 \pm 0.016$ \\
\hline $\mathbf{F}_{7}$ & $29.74 \pm 1.03$ & $0.37 \pm 0.009$ & $0.42 \pm 0.008$ & $11.90 \pm 0.86$ & $1.13 \pm 0.021$ \\
\hline$F_{8}$ & $31.47 \pm 0.98$ & $0.37 \pm 0.010$ & $0.43 \pm 0.009$ & $13.95 \pm 1.50$ & $1.16 \pm 0.020$ \\
\hline$F_{9}$ & $31.76 \pm 1.22$ & $0.38 \pm 0.013$ & $0.44 \pm 0.010$ & $13.63 \pm 0.99$ & $1.15 \pm 0.015$ \\
\hline
\end{tabular}

*n=6

\section{POST COMPRESSION PARAMETERS}

Table 9: Post compression parameters for Mucoadhesive buccal tablet

\begin{tabular}{|c|c|c|c|c|c|}
\hline $\begin{array}{c}\text { Formulation } \\
\text { code }\end{array}$ & $\begin{array}{c}\text { Hardness } \\
(\mathrm{Kg} / \mathrm{cm} 2)^{*}\end{array}$ & $\begin{array}{c}\text { Thickness } \\
\text { (mm)* }\end{array}$ & $\begin{array}{c}\text { Friability } \\
\text { (\%)* }\end{array}$ & $\begin{array}{c}\text { Weight variation } \\
\text { (mg)* }\end{array}$ & $\mathbf{p H}^{*}$ \\
\hline$F_{1}$ & $5.9 \pm 0.11$ & $3.21 \pm 0.011$ & $0.89 \pm 0.023$ & $248 \pm 1.04$ & $6.8 \pm 0.09$ \\
\hline$F_{2}$ & $5.8 \pm 0.12$ & $3.25 \pm 0.010$ & $0.82 \pm 0.014$ & $252 \pm 1.41$ & $6.6 \pm 0.11$ \\
\hline $\mathbf{F}_{3}$ & $5.6 \pm 0.10$ & $3.22 \pm 0.008$ & $0.40 \pm 0.017$ & $247 \pm 1.47$ & $6.7 \pm 0.08$ \\
\hline $\mathbf{F}_{4}$ & $5.5 \pm 0.12$ & $3.20 \pm 0.014$ & $0.40 \pm 0.034$ & $253 \pm 1.04$ & $6.6 \pm 0.10$ \\
\hline$F_{5}$ & $5.8 \pm 0.10$ & $3.25 \pm 0.011$ & $0.60 \pm 0.029$ & $250 \pm 1.94$ & $6.8 \pm 0.11$ \\
\hline$F_{6}$ & $6.0 \pm 0.11$ & $3.20 \pm 0.011$ & $0.40 \pm 0.021$ & $248 \pm 1.47$ & $6.7 \pm 0.14$ \\
\hline $\mathbf{F}_{7}$ & $6.0 \pm 0.14$ & $3.24 \pm 0.021$ & $0.56 \pm 0.026$ & $250 \pm 1.72$ & $6.8 \pm 0.12$ \\
\hline$F_{8}$ & $5.7 \pm 0.14$ & $3.21 \pm 0.011$ & $0.44 \pm 0.014$ & $247 \pm 1.41$ & $6.8 \pm 0.10$ \\
\hline$F_{9}$ & $5.9 \pm 0.13$ & $3.19 \pm 0.011$ & $0.40 \pm 0.026$ & $246 \pm 1.60$ & $6.7 \pm 0.08$ \\
\hline
\end{tabular}

\section{Drug content}

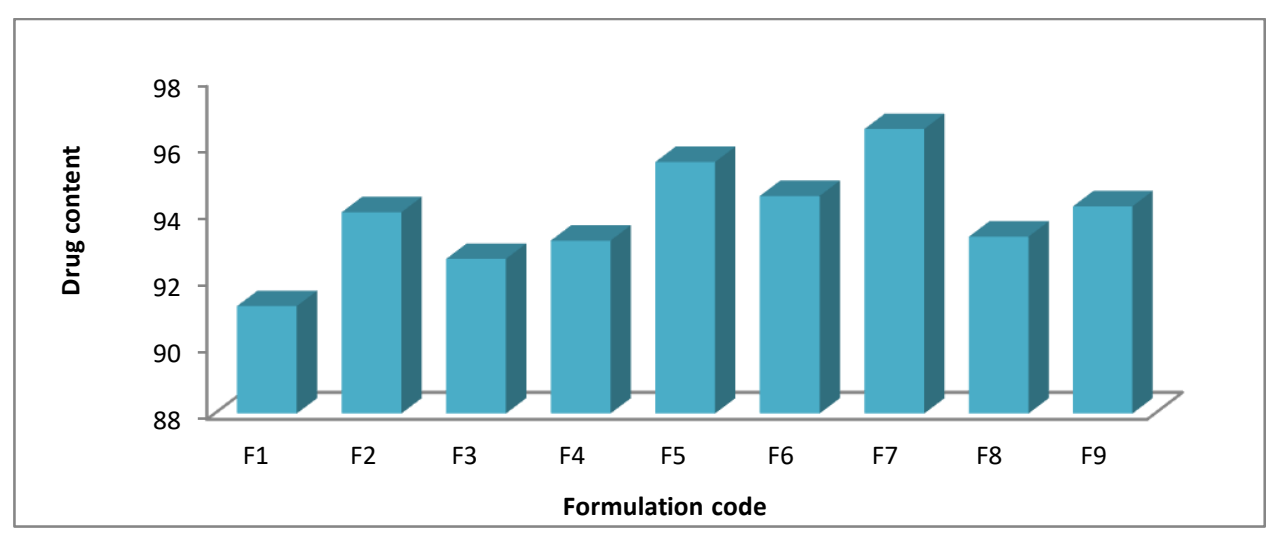

Figure 5: Graphical presentation of drug content 


\section{Swelling study}

The swelling index of Repaglinide buccal tablet for $8 \mathrm{hrs}$. The water uptake nature of the polymer is one of the important properties that affect the onset of swelling. Swelling index increases with increases concentration of the HPMC K100M and xanthan gum. The formulation $\mathbf{F}_{7}$ possessing highest swelling index.

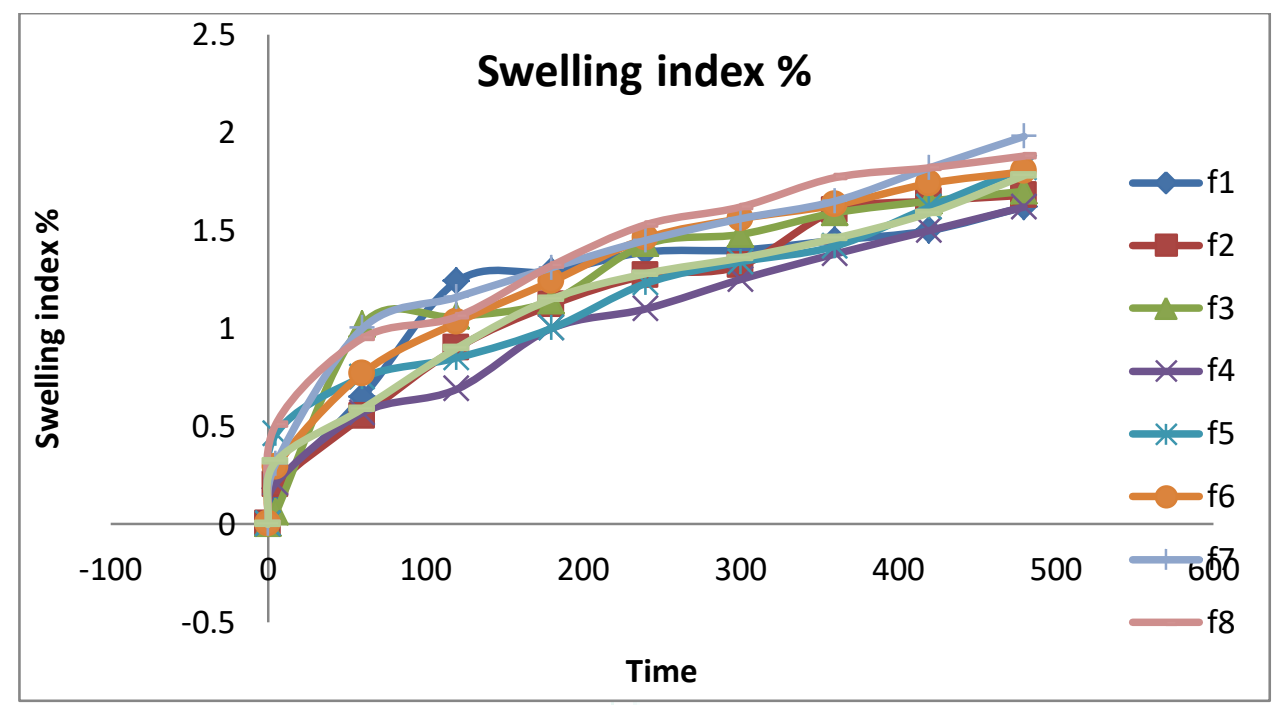

Figure 6: Graphical Presentation of swelling index

\section{Mucoadhesive strength}

The highest bioadhesion strength was possessed by the formulation containing HPMC K $100 \mathrm{M}$ and Xanthan gum. Increases in the concentration of HPMC K100 M and Xanthan gum increases bioadhesion strength of the formulation.

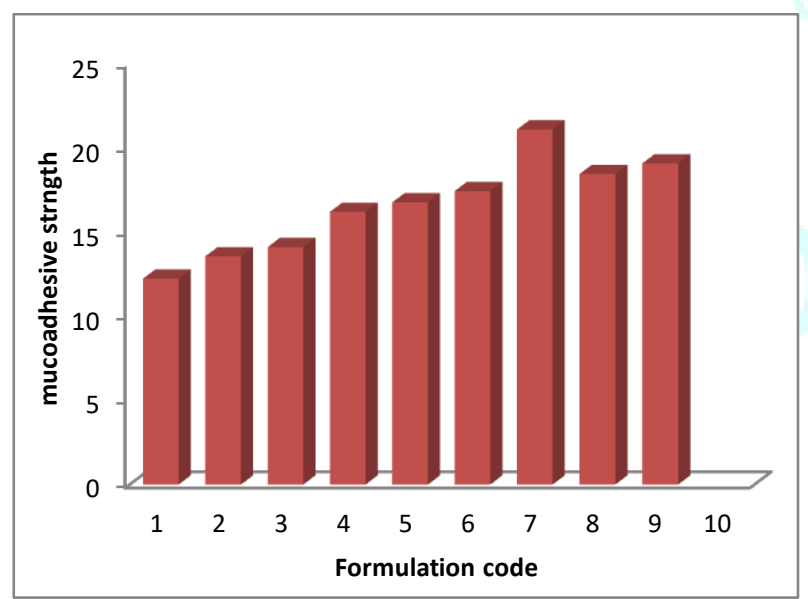

Figure 7: Graphical presentation of Mucoadhesive strength

\section{In-vitro dissolution study}

In -Vitro drug Release Studies of Repaglinide buccal tablets were determined using USP type II apparatus. The drug release was found to vary according to the ratio of mucoadhesive polymers. The formulation $\mathbf{F}_{7}$ showed the optimum drug release $96.21 \%$ at the end of $12 \mathrm{hrs}$ containing HPMC K100M and xanthan gum.

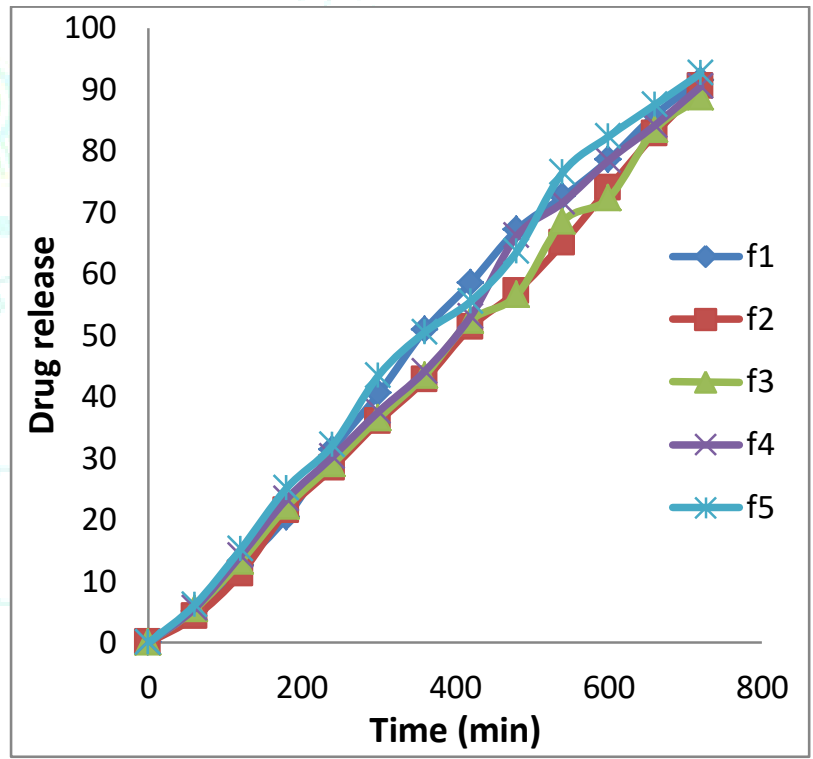

Figure 8: Graphical presentation of In-vitro drug release 


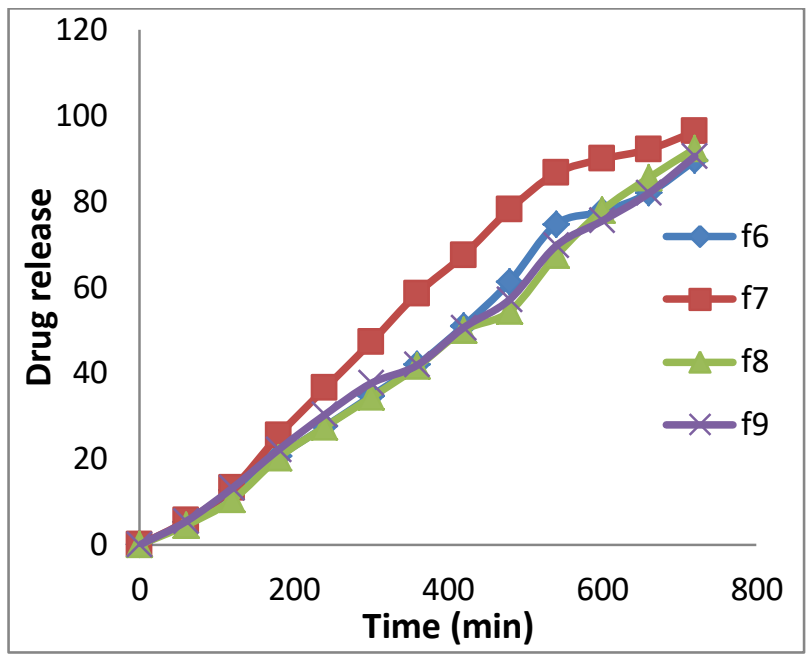

Figure 9: Graphical presentation of In-vitro drug release Optimization

A $3^{2}$ full factorial design was selected and 2 factors were evaluated at 2 levels, respectively. The percentage of HPMC K100M (X1) and Xanthan Gum (X2) were selected as independent variables and dependent variables drug release, swelling index, mucoadhesive strength. The data obtain were treated using design expert software and analyzed statistically using analysis of variance (ANOVA).

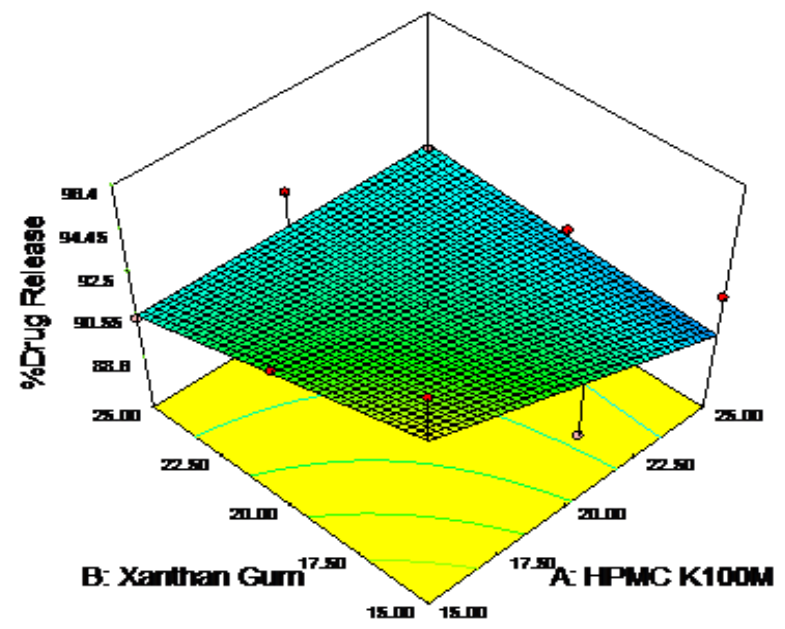

Figure 10: surface response plot showing effect of HPMC $\mathrm{K100M}$ and Xanthan Gum on drug release

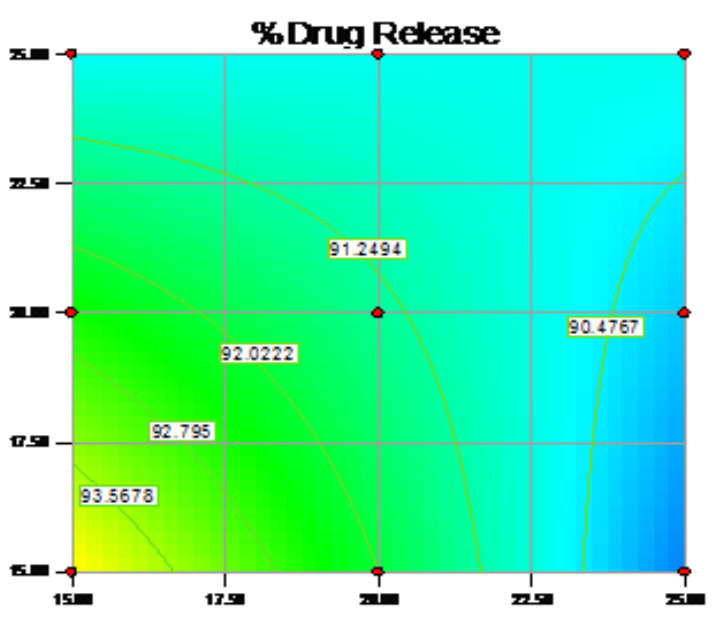

Figure 11: Counter plot showing effect of HPMC K100M and Xanthan Gum on drug release

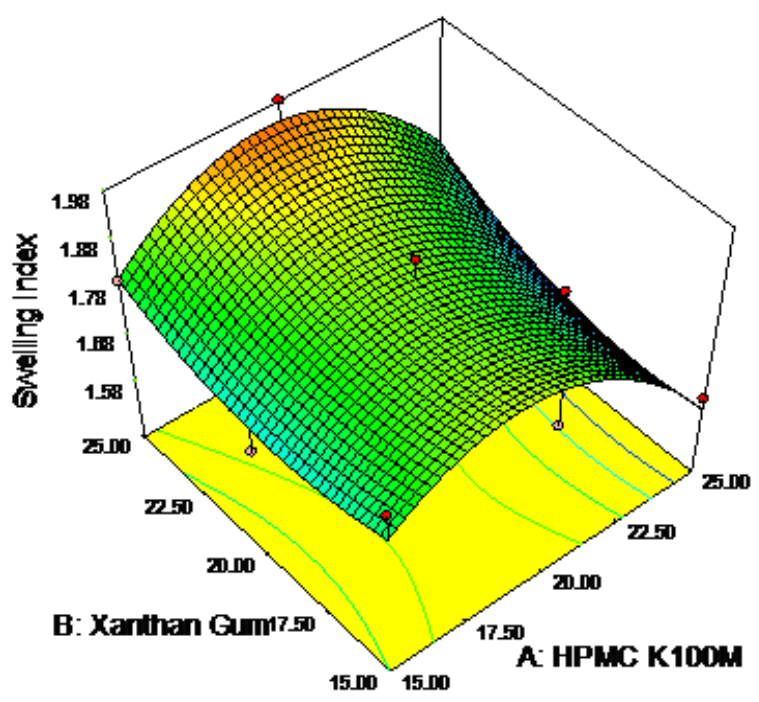

Figure 12: surface response plot showing effect of HPMC $\mathrm{K100M}$ and Xanthan Gum on swelling index

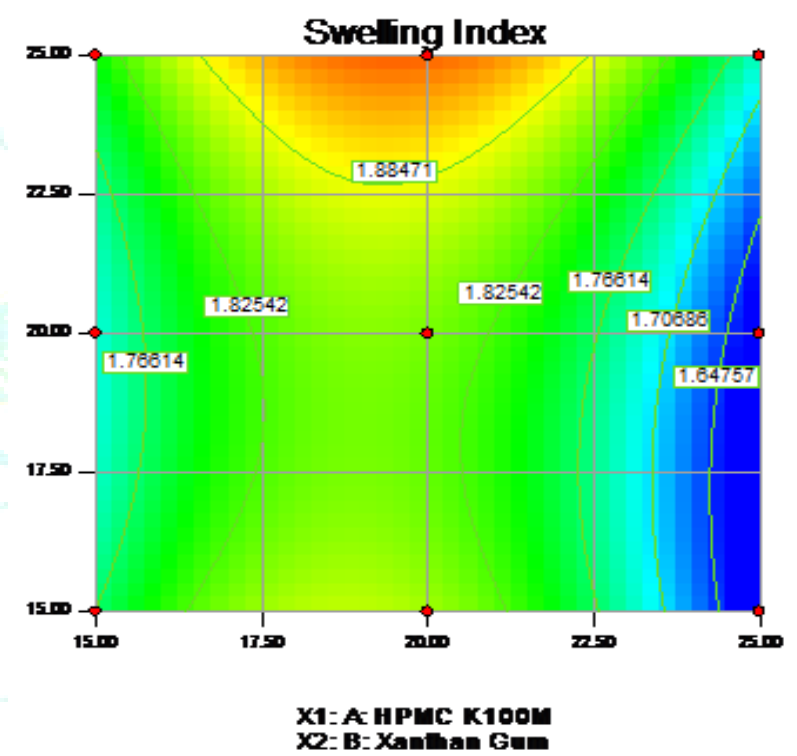

Figure 13: Counter plot showing effect of HPMC K100M and Xanthan Gum on swelling index

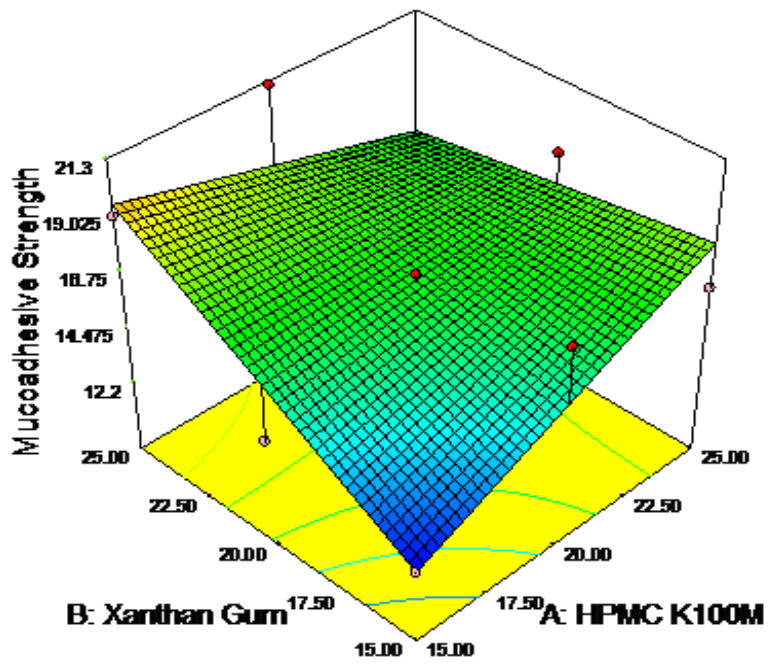

Figure 14: surface response plot showing effect HPMC K100M and Xanthan Gum on mucoadhesive strength 


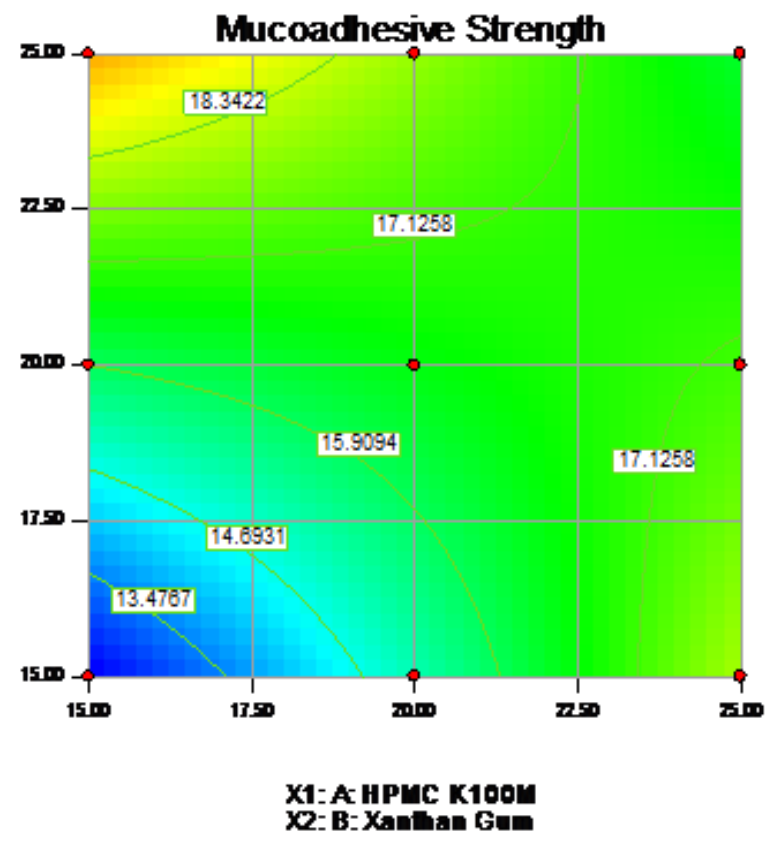

Figure 15: Counter plot showing effect of HPMC K100M and Xanthan Gum on mucoadhesive strength

From design expert optimum batch of HPMC K100M and Xanthan Gum was found to be optimized. From this data F7 was selected as optimized formulation.

\section{Kinetic Study}

In the present study, the drug released mechanism from all formulation and evaluation of mucoadhesive tablet formulation different kinetic models was analyzed using factorial design batches followed zero order , first order model kinetic, Highuchi and Korsemeyer's Peppas model kinetics.

Table 10: $\mathbf{R}^{2}$ values of Korsemayer's peppas model kinetics

\begin{tabular}{|c|c|c|c|c|c|c|c|c|c|}
\hline Batch & $F_{1}$ & $F_{2}$ & $F_{3}$ & $F_{4}$ & $F_{5}$ & $F_{6}$ & $F_{7}$ & $F_{8}$ & $F_{9}$ \\
\hline$R^{2}$ & 0.923 & 0.994 & 0.914 & 0.909 & 0.925 & 0.986 & 0.939 & 0.967 & 0.979 \\
\hline N Value & 0.523 & 0.562 & 0.589 & 0.526 & 0.549 & 0.563 & 0.578 & 0.512 & 0.545 \\
\hline
\end{tabular}

The classical zero order released curved was found to be linear the curve plotted according to first order and Highuchi were also found to be linear respectively. For the Korsemeyer's Peppas released curves $\mathrm{r}^{2}$ was found to be $\geq 0.90$ for all formulation and $\mathrm{n}$ value was found to be $\geq 0.5$ which indicate that all the formulation show anomalous or non-fickian diffusion. The drug release occurs probably by diffusion, erosion and dissolution follows.

Stability studies of Mucoadhesive buccal tablet of Repaglinide

Table 11: Stability study of optimized formulation

\begin{tabular}{|c|c|c|c|c|}
\hline \multirow{2}{*}{ Sr.No. } & Observations & \multirow{2}{*}{ Before Stability } & \multicolumn{2}{|c|}{ Stability testing interval days } \\
\cline { 3 - 5 } & & & 1 months & 2 months \\
\hline \multirow{2}{*}{$\mathbf{1}}$. & General appearance & & & \\
\cline { 2 - 5 } & Color & No change & No change & No change \\
\cline { 2 - 5 } & Odor & No change & No change & No change \\
\hline $\mathbf{2 .}$ & Ph & 6.4 & 6.5 & 6.4 \\
\hline $\mathbf{3 .}$ & \% Drug release & 96.35 & 96.15 & 95.80 \\
\hline $\mathbf{4 .}$ & \% Drug content & 96.50 & 97.05 & 96.87 \\
\hline
\end{tabular}

Optimized formulation $\mathbf{F}_{7}$ at $25{ }^{\circ} \mathrm{C}$ temperature was found to be stable up to 2 months. There was no significant change in appearance, drug release and drug content. 


\section{CONCLUSION}

It was planned in this investigation to formulate and evaluate mucoadhesive buccal tablet of Repaglinide to release the drug in buccal cavity for extended period of time in order to avoid first pass metabolism to reduce the dosing frequency and to improve the patient compliant. Experiments were conducted to investigate the influence of polymer like HPMC K100M and xanthan gum bioadhesion strength and release kinetic of mucoadhesive tablet of Repaglinide. In vitro dissolution studies were conducted in apparatus II at $50 \mathrm{rpm}$ for $12 \mathrm{hr}$. Drug content of all formulation were found to be more than $96.55 \%$. The $\mathrm{pH}$ of all mucoadhesive formulation was in between 6.7 to 6.8 . In vitro drug release result of all the formulation were conducted for $12 \mathrm{hrs}$ of all tablet formulation F1 -F9. The formulations F7 were taken as an optimized batch. It can be seen that by increasing the concentration of HPMC K100M and xanthan gum in the formulation, the drug release rate was found to be increased. The in vitro release kinetic indicate that all the formulation show anomalous or nonfickian diffusion. The drug release occurs probably by diffusion, erosion and dissolution follows. The data was statically analyzed and mechanism of release kinetic studied. All the studies were conducted at least 6 times and average was computed and tabulated.

\section{ACKNOWLEDGEMENT}

The authors are thankful to the principal and management of Loknete Dr. J. D. Pawar College of Pharmacy Manur, for providing necessary facilities to carry out this work.

\section{CONFLICT OF INTERESTS}

Declared None.

\section{REFERENCES}

1. Bobede N N, Atram S C, Wankhade V P, Pande S D, Tapar K K, A Review on Buccal Drug Delivery System, International Journal of Pharmacy and Pharmaceutical Science Research,2013; 3(1): 35-40.

2. Sonawane M, Shinkar DM, Saudagar RB, Mucoadhesive Buccal Drug Delivery System Review Article, International Journal of Current Pharmaceutical Research ISSN 0975-7066 Vol 9, Issue 4, 2017.

3. Rao NGR, Shravani B, Reddy MS, Overview on Buccal Drug Delivery Systems, Journal Sciences And Research Vol.5(4), 2013, $80-88$

4. Gite SS, Shinkar DM, Saudagar RB, Mucoadhesive buccal drug delivery, An Overview Journal of Advanced Pharmacy Education \& Research Oct-Dec 2013 Vol 3 Issue 4.

5. Gupta SK, Singhvi IJ, Shirsat M, Karwani G, Agarwal A Agarwal A, Buccal Adhesive Drug Delivery System, A Review Asian Journal of Biochemical and Pharmaceutical Research Issue 2 (Vol. 1) 2011.

6. Lokhande SS, Lahoti SS Buccoadhesive Drug Delivery System, Need Asin Journal Of Biomedical And Pharmaceutical Sciences Volume 2, Issue 14, 2012.
7. Shinkar DM, Aarif SK, Soudagar RB, Formulation and Evaluation of Mucoadhesive Buccal Tablet of Miconazole Nitrate, European Journal of Biomedical AND Pharmaceutical sciences 2016; 3, (10): 205-212.

8. Shinkar DM, Gadakh RS, Saudagar RB, Mucoadhesive Tablet of Losartan Potassium For Unidirectional Buccal Drug Delivery, Development And Evaluation European Journal of Biomedical And Pharmaceutical Sciences 2016; 3 (9): 242-251.

9. Sandhya P, Spoorthy PV, Susmitha A, Safooratalat, Ashwin K, Kumar GG, Formulation and Evaluation of Mucoadhesive Buccal Tablet of Losartan By Using Natural Polymers, International Journal of Pharmacy And Analytical Research, April-June-2016; 5 (2): 239-244.

10. Biswal B, Karna N, Bhavsar B, Formulation and Evaluation of Repaglinide Buccal Tablet: Ex Vivo Bioadhesion Study and Ex Vivo Permeability Study Journal of Applied Pharmaceutical Science 2014; 4 (05): 096-103.

11. Nikunj B, Modi D, Dr. Bhardia PD, formulation, development and evaluation of sustained release matrix tablets of Repaglinide, international journal of pharmaceutical research and bio-science, 2014; 3(2): 370-396.

12. Sarfaraz MD, Reddy BL, Doddayya H, Udupi RH, Design and inVitro Evaluation of Gastro Retentive Floating Tablets of Repaglinide, Int. J. Drug Dev. \& Res., July-September 2013, 5 (3): 322-332.

13. Patel DM, Pratik, Shah M, Patel CN, Formulation and evaluation of bioadhesive buccal drug delivery of repaglinide tablet, Asian Journal of Pharmaceutics, July-Sep 2012; 2 (6): 171-179.

14. Ranade A.N , Ranpise N.S, Sanap G.S and Kulkarni R.R Development and In Vitro Evaluation of Buccal Tablet of Quinapril Hydrochloride Indian Journal of Pharmaceutical Education and Research, Oct-Dec, 2011; 45(4): 364-369.

15. Krishna VR, Sudhan Rao YM, Reddy PC, Sujatha K, Formulation and In-vitro evaluation of Buccoadhesive tablets of Furosemide International Journal of Drug Development \& Research Oct-Dec 2011, 3(4): 351-361

16. Velmurugan S, Deepika B, Nagaraju K, Sundar V, Formulation and In-Vitro Evaluation of Buccal Tablets of Piroxicam international Journal of Pharm tech Research 2010; 2 (3): 1958-1968.

17. Arya RK, Garud A, Jain NK, Garud N, development and Evaluation of Mucoadhesive Buccal Tablets of Salbutamol Sulphate international Journal of Pharmacy and Pharmaceutical Sciences 2010; 2 (2): 40-42.

18. Kadam PB, Dias RJ, Mali KK, Havaldar VJ and Mahajan NS, Formulation and Evaluation of buccoadhesive tablets of Atenolol Journal of Pharmacy Research 2008; l (2): 193-199.

19. https://www.drugbank.ca/drugs/DB00912

20. https://en.wikipedia.org/wiki/Repaglinide.

21. Indian Pharmacopoeia, Government of India, Ministry of health and family welfare, Indian pharmacopoeia commission, Ghaziabad; 2014, Vol. III, Page no-2651

22. The Merck Index, An Encyclopedia of chemicals, Drug and Biological 14th Edition, Published by Merck research laboratory copyright 2006 by Merck and Co.Inc. Whitehouse station, NjUsa, Page No:1402

23. Tripathi KD, Essentials of Medical Pharmacology, $6^{\text {th }}$ Edition; Jaypee Brother's Medical publishers Pvt.Ltd, New Delhi; 2006, Page no. 266-273. 